\title{
Brain Stem Glioblastoma
}

National Cancer Institute

\section{Source}

National Cancer Institute. Brain Stem Glioblastoma. NCI Thesaurus. Code C5097.

A glioblastoma that arises from the brain stem. 